\title{
Peculiarities of the agricultural business appraisal approach in the project finance in the pandemic situation
}

\author{
Elizaveta Markovskaya ${ }^{1 *}$ and Angela Mottaeva ${ }^{2,3}$ \\ ${ }^{1}$ National Research University Higher School of Economics, 16, ul. Souyza Pechatnikov, Saint \\ Petersburg, 190008, Russia \\ ${ }^{2}$ Moscow Moscow State University of Civil Engineering, 26 Yaroslavskoye Shosse, 109377, \\ Moscow, Russia \\ ${ }^{3}$ Moscow Region State University, Radio str., 10A, 105005, Moscow, Russia
}

\begin{abstract}
According to modern survey many entrepreneurs noted the negative consequences of the pandemic: $76 \%$ reported a decrease in revenue, $66 \%$ a decrease in demand for goods or services, $36 \%$ a decrease in the number of suppliers, $24 \%$ a decrease in the number of branches or points of sale. Every third entrepreneur (34\%) sent employees on unpaid vacation, and every fifth $(18 \%)$ had to resort to dismissing employees. Most entrepreneurs do not expect to return to pre-crisis indicators in the short term. Currently, in connection with the situation related to the coronavirus infection pandemic, new approaches are emerging in the field of business valuation and consulting, developed in practice by institutions involved in business appraisal, project, and corporate finance issues. The paper based on the case from Russian fitness industry examines the transformation of the business appraisal approach in project finance in the pandemic situation. The author analyses the recommendations of the Russian and foreign experts in the field of business appraisal and project finance and apply them to the case from the fitness industry.
\end{abstract}

\section{Introduction}

According to a NAFI poll published on July 3, more than half of entrepreneurs (54\%) indicated that their company was able to continue working in some form during the period of self-isolation. $46 \%$ of entrepreneurs transferred their employees to a remote format [1].

Many entrepreneurs noted the negative consequences of the pandemic: $76 \%$ reported a decrease in revenue, $66 \%$ - a decrease in demand for goods or services, $36 \%$ - a decrease in the number of suppliers, $24 \%$ - a decrease in the number of branches / points of sale. Every third entrepreneur (34\%) sent employees on vacation at their own expense, and every fifth $(18 \%)$ had to resort to dismissing employees. Most entrepreneurs do not expect to return to pre-crisis indicators in the short term: $36 \%$ expect to return to the previous level not earlier than in a year, $21 \%$ - in 2-3 years. A third of entrepreneurs are more optimistic: $35 \%$ expect

* Corresponding author: markovskaya@yandex.ru 
to return to pre-crisis levels in a few months or earlier, and $8 \%$ note that the coronavirus has not affected their work. The majority of business representatives (70\%) took measures to adapt to the crisis situation. The TOP-3 of such measures include budget cuts for current spending, switching to online and price / tariff adjustments. Most of those who transferred their business online (60\%) believe that this has helped the company become more effective. Despite the difficulties, many entrepreneurs did not change their strategic plans for the future: $52 \%$ reported that quarantine did not affect their business plans, and $8 \%$ noted that thanks to self-isolation, they found new ideas and business formats. $40 \%$ of entrepreneurs reported that plans had to be changed after all

In connection with the development of the coronavirus pandemic, in the business appraisal and investment project evaluation process, when forecasting cash flows, the following should be considered:

- The importance of expert methods is increasing

- Uncertainty complicates forecasting

- The income approach to business valuation becomes difficult to apply

- It is necessary to take into account new business models based on the online formats that appear in some enterprises in a new situation

\section{Research Design, Methodology, and Data Analysis}

An analysis of the recommendations of Russian and international expert communities highlights the following, most important issues in relation to conducting a business assessment during a coronavirus pandemic:

1. Form financial models for a 2-year cycle, use zero economic growth in 2 years and establish annual inflation at the level of $5-7 \%$.

2. The Scenario analysis is crucial to assess and account for the likelihood that the crisis will last for 3, 6, 12, 18 months or more.

3. It is necessary to take into account the possibilities of financing and the availability of credit funds, including the risks of breach of loan obligations. /

4. This approach may not be appropriate for recent transaction prices, especially those performed before the pandemic spread, to receive reliable data in determining fair value. /

5. Care should be taken to avoid "double counting" of the valuation inputs in both the comparative calculation and the income approach. Using the discounted cash flow (DCF) method, if future cash flows have been adjusted downward, the increase in the discount rate may not be as large as the increase in the discount rate if the cash flows have not been adjusted for the effects of the crisis. /

6. During a pandemic, the performance indicators differ markedly from retrospective data in the direction of gradual deterioration. The degree to which the performance indicators differ from retrospective indicators during a pandemic is primarily determined by:

- belonging to a specific industry / field of activity: for example, deterioration in performance is less affected by the production and distribution of food / medicine.

- parameters of restrictive measures introduced in a specific area such as intensity and timing.

- terms of the concluded agreements .

7. It is possible to use data from China and other countries that faced COVID-19 before Russia did. [2-8].

As an additional method that is suitable for evaluating investment projects in a situation of uncertainty, we propose to use the fuzzy logic method.

The main idea of the method of fuzzy sets (fuzzy logic) is that the individual patterns of a person's thinking are not numbers, but elements of some sets. It is possible to characterize the belonging of an element to a set with a certain degree of reliability. The function at any 
given time can take on a different form. For calculations, it is more convenient to use a function of a certain type. A set is a collection of any objects (elements) that have common properties. In ordinary set theory, the belonging of any element $\mathrm{X}$ to a certain set A can be represented by two values: 1 - belongs or 0 - does not belong. The statement that the element $\mathrm{x}$ is included or not included in the set A can be expressed using the function $\mu(\mathrm{x})$, which has the following form:

$$
\mu(x)=\left\{\begin{array}{l}
1, \text { if } x \in A \\
0, \text { if } x \notin A
\end{array}\right.
$$

The fuzzy logic method involves the complication of the traditional approach to calculating the NPV indicator in the process of investment projects assessment :

1) Traditional approach to the NPV evaluation :

$$
N P V=\sum_{t=1}^{n} \frac{C F_{t}}{(1+i)^{t}}-I_{0}=P V-I_{0}
$$

2) Fuzzy logic approach:

The formula for calculating the range of values of the NPV indicator under the condition of planning 3 scenarios such as optimistic, pessimistic, and basic can be presented as follows:

$[$ NPV pessimistic, NPV basic, NPV optimistic $]=[\mathrm{PV}$ pessimistic - I pessimistic $]$; $[\mathrm{PV}$ basic - I basic];[PV optimistic - I optimistic] (3)

Scenarios are a set of values of NPV indicators that are predicted by the method of expert assessments (or in another way) taking into account certain conditions of the internal and external environment.

We also consider it necessary to adapt the risk management system during the pandemic, taking into account the specifics of the business.

Thus, in a pandemic situation, when preparing a project for financing, special attention should be paid to the following areas in the investment analysis:

1. Market analysis. It should take into account the specifics of the purchasing power of the population in a difficult period, and the macroeconomic situation and changes associated with it.

2. Forecasting cash flows. The next step is the construction of projected cash flows. It is advisable to apply the scenario method, sensitivity analysis, and fuzzy logic method when constructing projected cash flows. The historical data should be adjusted to reflect the change in the revenue side of the project due to the pandemic. When forecasting, it is advisable to rely on the experience of other countries and similar industries that are also experiencing this situation.

3. Risk management system. It is necessary to adapt the risk management system to the pandemic situation. It is pivotal to include measures that allow managing and, if possible, leveling the risks associated with the negative consequences of the coronavirus pandemic.

The recommendations described above were applied in the preparation for project financing of an investment project from the fitness industry. The author of this paper is participating in this project as a business consultant. The project consisted of expanding the existing network of fitness centers in the form of creating a new club of 1,500 sq. m. with a swimming pool and SPA zone in one of Russia's regions. The financing strategy consisted in attracting a loan from the bank in the format of project financing $(80 \%$ of the investment project value) and investing its own funds (20\%).

The following features of business and project assessment were identified in the process of preparing it for project financing in the pandemic situation. 
1) the method of scenarios and the sensitivity analysis in combination with the approach of fuzzy logic were used due to uncertainty and changing conditions of both the financing and the structure of the transaction

2) cash flows were predicted taking into account the loan term, a decrease in the growth rate of household income, and including online programs and outdoor activities.

3) the risk management system provided for the following activities in the already existing clubs of the network to maintain cash flow:

- conducting classes online and outdoors to retain network customers

- a pre- sale of season tickets to the existing clubs of the network, as well as to new clubs

4) The forecast took into account the experience of business partners from Europe.

In this paper, the following main project data are presented.

\section{Results/Findings and Discussion}

The features of business and project assessment were identified in the process of preparing it for financing in the context of the coronavirus pandemic. Let us consider sequentially how the sections of the project business plan (based on the case from the fitness industry) were adapted in the process of preparing for project financing.

\subsection{Market analysis}

The part of the market analysis from the business plan of the investment project based on the case from the fitness industry is illustrated in italics below. Modern trends in the development of the fitness industry market including pandemic situation are highlighted in the text.

The main trends in the development of the fitness industry in Russia

According to Busines Stat estimates, the value of the Russian fitness services market in 2014-2018 almost doubled from 31.5 billion rubles to 61.3 billion rubles. These indicators directly include the cost of paid classes but do not take into account additional services of fitness centers: massage, spa, visits to fitness bars, etc. The growth in market turnover occurred against the background of a decrease in real incomes of the population and the average price of an annual membership. Revenue grew due to an increase in the number of consumers of fitness services and the average annual number of visits to fitness centers per client. In 2014-2018, the number of consumers of fitness services in Russia increased from 3.6 million people to 5.4 million people. Approximately $58.5 \%$ of all clients in the fitness industry live in Moscow and St. Petersburg. The growth in the number of fitness center customers was due to the expansion of federal chains and the emergence of a large number of facilities in residential areas. However, in recent years, there has been an increase in the number of economy-format fitness clubs, which also contributed to an increase in the availability of services for the population. The development of an economy format of fitness centers, and the growth of the territorial and financial availability of these establishments, make it possible to predict market growth. In 2023, the Russian market of fitness services in value terms will be 113.1 billion rubles, which is 1.8 times higher than the level of 2018. In the next 5 years, the following trends will be observed in the market: the further development of franchise networks, an increase in the number of automated clubs with a minimum number of staff, an increase in demand for programs for the elderly and rehabilitation programs. Due to the coronavirus pandemic, many fitness centers have begun developing programs that can be implemented online. According to unofficial statistics, about $13 \%$ of the Russian population does sport on-line.

Forecasting cash flows 


\subsection{Scenario approach}

3 possible scenarios were analysed:

1. Basic scenario (detailed and presented in this business plan)

It assumes a 5\% increase in prices and an increase in some types of costs in monetary terms (payroll, utilities) at an average of $4-5 \%$ per year.

2. An optimistic scenario.

It assumes that the rise in prices for fitness services will outpace the growth in tariffs for utilities, and the wage bill growth

3. Pessimistic scenario.

Calculated at constant prices. It assumes that any increase in the cost part of the project will be offset by an increase in the revenue part.

Table 1 shows the results of a comparative analysis of the main performance indicators of the project in the implementation of each of the scenarios.

The analysis of project performance indicators, taking into account possible scenarios, allows us to conclude that any scenario keeps the project cost effective.

Table 1. Main performance indicators of the investment project.

\begin{tabular}{|c|c|c|}
\hline Scenario & $\begin{array}{c}\text { Discounted CF for 7 years. mln } \\
\text { RUR }\end{array}$ & NPV .mln RUR \\
\hline Basic & 85.8 & 51.4 \\
\hline Pessimistic & 67.1 & 32.7 \\
\hline Optimistic & 110.8 & 76.4 \\
\hline
\end{tabular}

\subsection{Sensitivity analysis}

The sensitivity analysis shows that the project is especially sensitive to changes in the project's revenues and costs, involving operating expenses and investment costs. Therefore, a scenario assuming moderate growth in both prices and costs was chosen as the baseline. This is the basic scenario in the business plan. The company also planned to use the following measures as a set of risk management measures:

- all contracts have fixed prices;

- in order to prevent a decrease in revenue during the period of the coronavirus pandemic, the company promptly notifies its customers about the sanitary and hygienic measures being taken and on-line sports programs.

Table 2 shows the results of a sensitivity analysis.

Table 2. Results of the sensitivity analysis.

\begin{tabular}{|l|l|l|l|}
\hline MIn. RUR & & 1 & 2 \\
\hline $\begin{array}{l}\text { Changes in discount } \\
\text { rate }\end{array}$ & $3 \%$ & - & - \\
\hline Discount rate & $11 \%$ & $8 \%$ & $14 \%$ \\
\hline NPV проекта. NPV & 51.4 & 61.3 & $\mathbf{4 3 . 1}$ \\
\hline changes & $10 \%$ & - & - \\
\hline Return & $100 \%$ & $90 \%$ & $110 \%$ \\
\hline NPV & 51.4 & $\mathbf{3 2 . 1}$ & 77.3 \\
\hline Prices & $100 \%$ & $0 \%$ & $10 \%$ \\
\hline NPV & 51.4 & $\mathbf{3 7 . 9}$ & 65.4 \\
\hline Operational Costs & $100 \%$ & $0 \%$ & $10 \%$ \\
\hline NPV & 51.4 & 56.6 & $\mathbf{4 4 . 0}$ \\
\hline Fixed investment costs & $100 \%$ & $10 \%$ & $20 \%$ \\
\hline NPV & 51.4 & $\mathbf{4 4 . 2}$ & $\mathbf{4 4 . 5}$ \\
\hline
\end{tabular}




\subsection{Fuzzy logic method}

NPV values were calculated for 3 scenarios. The owner has determined that the most acceptable NPV values of the project lie in the interval [NPV base; NPV optimistic]. Graphically, this interval can be represented as the area of a triangle, the base of which is the segment N2-N3 (Fig.1).

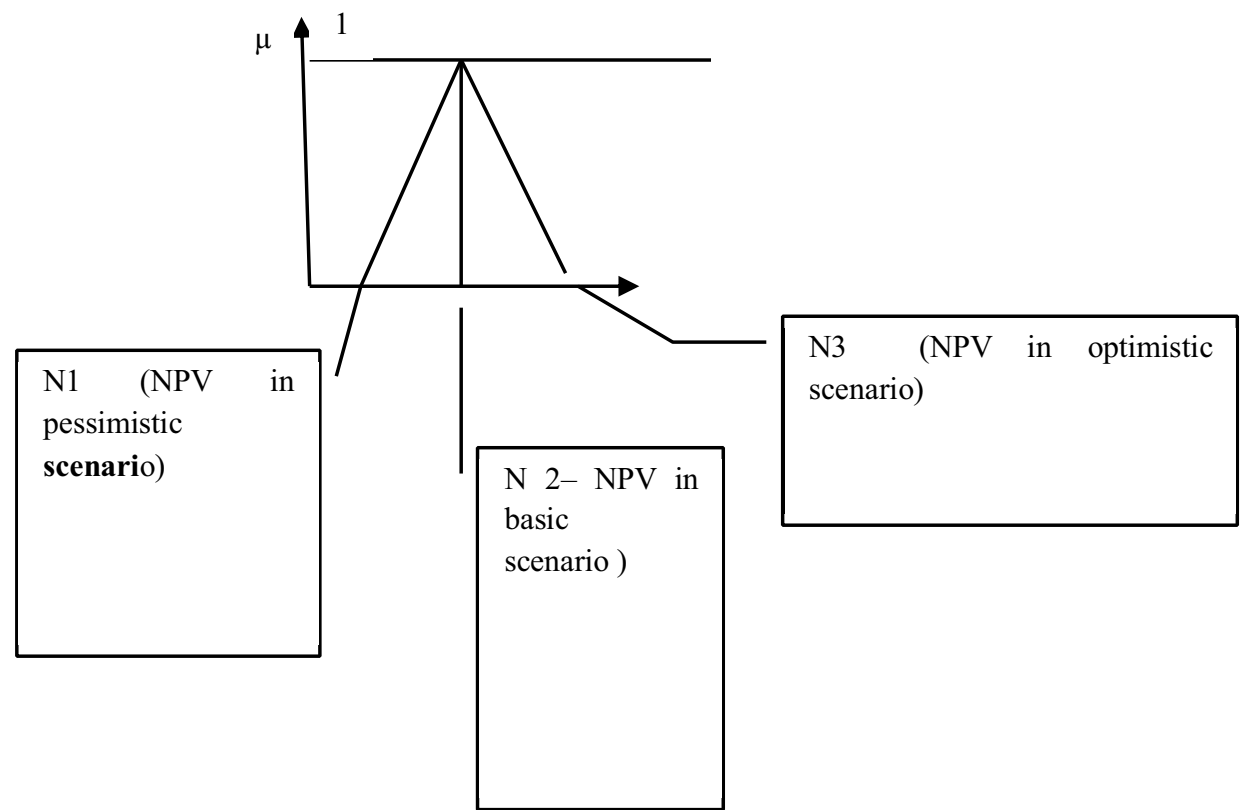

Fig. 1. Intervals for NPV in different scenarios.

\subsection{The project risk management system related to the situation of the coronavirus pandemic}

The risk of a prolonged period of the coronavirus pandemic and the resulting risks (a decrease in revenue, customer churn, etc.) were specified as the main specific risk. The risk is manageable, since the company has provided a set of measures to reduce this risk including: strengthening sanitary and hygienic measures, and developing online sports programs for the provision of fitness services remotely(See Table 3).

Table 3. Measures for keeping sustainable cash flow.

\begin{tabular}{|l|l|l|}
\hline \multicolumn{1}{|c|}{ measure } & \multicolumn{1}{|c|}{ Aim and description of the measure } & \multicolumn{1}{c|}{ result } \\
\hline On-line training & $\begin{array}{l}\text { Aim - to save the current clients } \\
\text { On-line trainings are offered free of charge }\end{array}$ & $\begin{array}{l}\text { The enterpe } \\
\text { managed to keep the } \\
\text { current clients. }\end{array}$ \\
\hline Outdoor trainings & $\begin{array}{l}\text { Aim - to save the current clients and attract new } \\
\text { ones. }\end{array}$ & $\begin{array}{l}\text { The enterprise } \\
\text { managed to keep the } \\
\text { current clients and } \\
\text { attract new ones. }\end{array}$ \\
\hline $\begin{array}{l}\text { Sales of the } \\
\text { membership cards } \\
\text { via call-center by } \\
\text { distance and on-line }\end{array}$ & Aim - to fulfill sales plans and keep cash flow. & $\begin{array}{l}\text { In April and in May } \\
\text { only 60\% of sales } \\
\text { targets were met. }\end{array}$ \\
\hline
\end{tabular}


In the business plan, when preparing for project financing, the following was taken into account:

1) the scenario method was applied; sensitivity analysis combined with the approach of fuzzy logic due to uncertainty and changing conditions of financing and the structure of the transaction was carried out;

2) cash flows were predicted taking into account the lending period, a decrease in the growth rate of household income, and new business formats such as online programs and outdoor activities;

3) the risk management system provided for the following activities in the clubs to maintain cash flow:

- conducting classes online and in the open air to retain customers

- the remote sale of subscriptions

- During the pandemic situation, when preparing for project financing, expert assessment methods come to the fore, including the fuzzy logic, and scenario methods, and the sensitivity analysis

It is necessary to take into account and conduct a detailed analysis of the market taking into account changes in the macroeconomic situation

Projected cash flows need to take into account flows from new activities associated with new formats (new on-line formats). At the same time, we will not necessarily see a decrease in cash flows in the forecast period.

- The risk management system should provide measures ensuring the financial stability of the business in order to present the bank with sustainable cash flow to pay off the debt.

- The bank, most likely, when making a decision in a situation of uncertainty, will focus on the indicators of the pessimistic scenario

\section{Conclusion, Contribution, and Implication}

In the result of our survey we may conclude:

- During a pandemic situation, when preparing for project financing, expert assessment methods come to the fore, including the fuzzy logic, and scenario methods, and the sensitivity analysis

- It is necessary to take into account and conduct a detailed analysis of the market taking into account changes in the macroeconomic situation

- Projected cash flows need to take into account flows from new activities associated with new formats (new on-line formats). At the same time, we will not necessarily see a decrease in cash flows in the forecast period.

- The risk management system should provide measures ensuring the financial stability of the business in order to present the bank with sustainable cash flow to pay off the debt.

- Analyzing the presented scenarios, the bank, most likely, when making a decision in a situation of uncertainty, will focus on the indicators of the pessimistic scenario

All the above mentioned recommendations developed by international and Russian experts can be used in preparing for project financing in an adapted format, taking into account the specifics of the business, the macroeconomic situation, and the requirements of the bank.

\section{References}

1. Business after pandemic situation:recovering after shock, 
https:/nafi.ru/analytics/biznes-posle-pandemii-vosstanovlenie-ot-shoka/

2. Methodology of business appraisal in the pandemic situation, https://srosovet.ru/activities/Metod/pandemic/MR_pandemiya_actual/

3. COVID-19: Navigating volatility distress, https://www2.deloitte.com/global/en/pages/about-deloitte/articles/covid-19-navigatingvolatility-and-distress.html

4. Message from TEGoVA concerning valuation during the Pandemic, https://www.tegova.org/data/bin/a5e78e8f60c448_TEGoVA.Message_from_the_Board 23.03.2020.pdf

5. Recommendations of the Institute of Appraisals of Canada, https://www.aicanada.ca/members-home/covid-19/

6. Recommendations of Cushman and Wakefield, https://www.cwrussia.ru/cwiq/reviews/obzory-rynka-rossii/trendsradar/

7. E. Bagreeva, A. Mottaeva, E3S Web of Conferences 210, 17024 (2020), https://doi.org/10.1051/e3sconf/202021017024

8. A.V. Bataev, et al., Proceedings of the 32nd International Business Information Management Association Conference, IBIMA 2018 - Vision 2020: Sustainable Economic Development and Application of Innovation Management from Regional expansion to Global Growth (2018) 